\title{
¿QUÉ HUMOS IDEOLÓGICOS HAN ENTRADO EN EL PONTIFICIO CONSEJO DE JUSTICIA Y PAZ?
}

ANTONIO PANCORBO DE RATO*

No es ninguna pregunta retórica. Realmente uno se acerca a los documentos del Pontificio Consejo de Justicia y Paz y, por un lado, encuentra reflexiones morales de máxima utilidad sobre temas sociales y económicos. Pero por otro, encuentra entreveradas una serie de propuestas técnicas, sobre las que la Doctrina Social de la Iglesia reitera no tener competencia, pero que el Pontificio Consejo de Justicia y Paz no duda en proponer de todas formas. Soluciones técnicas donde la organización coactiva de la economía por el Estado se antepone a una reflexión que dé primacía a la conciencia libre de los individuos (de la cual parece desconfiar) y a la actuación de los grupos intermedios en los que los individuos se articulan en sociedad, empezando por la familia.

La última Nota que el Pontificio Consejo de Justicia y Paz ha preparado para estimular el debate en la próxima reunión del G20 (Cannes, 3 y 4 de noviembre de 2011) es un buen ejemplo. El título puede haber dejado atónito a más de uno (puede que incluso al mismo Papa): «Por una reforma del sistema financiero y monetario internacional en la prospectiva de una Autoridad pública con competencia universal» (texto de la Nota, traducción no oficial). Una vez más, las soluciones técnicas que proponen hablan de más Estado. Ante la deriva que están tomando los Estados modernos en la promoción de la justicia y la paz, la Nota propone una «Autoridad con horizonte planetario», «dotada de

\footnotetext{
* Doctor en Economía, en la actualidad desempeña sus funciones en el Banco de España.
} 
estructuras y mecanismos adecuados». No lo llama «Estado Supranacional», pero sí le aplica el principio de subsidiariedad, propio de las relaciones de los ciudadanos con el Estado, y el símil que hace entre los individuos y los Estados con esta nueva Autoridad hacen pensar que se está proponiendo un «Estado de competencia planetaria».

La Doctrina Social de la Iglesia es parte de la teología moral, y no puede dar recetas de técnica política y económica. Los obispos, por tanto, no tienen por qué saber mucho de economía. Pero tampoco se pueden dejar aconsejar por seudoeconomistas, aprendices de brujos con la varita mágica del poder invasivo del Estado que todo lo resolverá por decreto legislativo, sin esfuerzo ni trabajo.

\section{I ¿NO ES JESUCRISTO EL REY DEL UNIVERSO?}

Lo primero que llama la atención es que una propuesta del Magisterio sobre una «Autoridad pública con competencia universal» no gire en torno a la idea de que la única «Autoridad» con competencia universal es Dios, y de ahí llegar a las conclusiones que sean. «Decid entre las gentes: ¡Yahvé es rey! El orbe está seguro, no vacila; Él gobierna a los pueblos rectamente» (Sal 96, 10). Esta idea, por supuesto, no debe conducir a plantear ningún tipo de régimen teocrático, pero sorprende que ideas como Jesucristo, Rey del Universo, o el derecho natural no solo no sean la base del razonamiento, sino que estén ausentes de la Nota.

El Pontificio Consejo habla de «crear», de «constituir» una Autoridad pública mundial, no de descubrir y reconocer por todos los pueblos las leyes que Dios ha inscrito en el corazón del hombre. La propia Nota se puede considerar un buen ejemplo de la denuncia que ella misma hace sobre «la cerrazón a un más allá, comprendido como algo más, respecto a la técnica». 
II

\section{PROPUESTAS TÉCNICAS MUY DISCUTIBLES}

Una de las propuestas de la Nota que más eco ha tenido en la prensa ha sido la de crear un «Banco Central Mundial», "que regule el flujo y el sistema de los intercambios monetarios con el mismo criterio que los bancos centrales nacionales». La Nota denuncia que «en la última parte del siglo anterior, la moneda y las actividades financieras a nivel global crecieron mucho más rápidamente que las producciones de bienes y servicios». Sin embargo, es conocido que este crecimiento desmesurado de la moneda y el crédito encuentran su origen, nada más y nada menos que en la lógica de los bancos centrales nacionales actuales para expandir la moneda y proteger a los bancos comerciales para que, a suvez, expandan el crédito. La misma lógica que los autores dicen que quieren replicar pero a escala universal como solución a los problemas creados por los bancos centrales nacionales. No es que estemos en contra de los bancos centrales. Tienen su función como garantes de la estabilidad de la oferta monetaria, banqueros del Estado y reguladores bancarios. Lo que ponemos en duda es la oportunidad de querer replicar a escala planetaria, sin ningún tipo de cambio o replanteamiento, unas instituciones que claramente han fracasado en el control de la moneda y el crédito, y esperar ver en esa mega-institución la solución, con la acumulación de poder político y económico que tal mega-institución acarrearía.

La Nota apunta con acierto a la expansión del crédito, mucho más rápida que la producción de la economía, la excesiva cantidad de moneda y la espiral inflacionista como las tendencias más perniciosas para la economía global y origen de la actual crisis financiera mundial. ¿Qué ha hecho que esto haya sido posible, solo razones éticas o también ha habido razones técnicas que han debilitado la ética y exacerbado la codicia ante la posibilidad para algunos de hacerse con los recursos de todos los demás? ¿Qué ha ocasionado que se formen las bolsas excesivas de liquidez y las burbujas especulativas que denuncia? ¿Ha jugado algún papel el diseño de las actuales instituciones públicas y privadas que dan soporte al sistema crediticio y monetario, o este 
diseño era el que demandaba la justicia y la paz, y lo que ha faltado han sido estructuras políticas y monetarias de la misma naturaleza y diseño, pero con poder planetario como las que propone la Nota?

En el proceso que propone la Nota de «recuperar la primacía de lo espiritual y de la ética y, con ello, la primacía de la política, responsable del bien común, sobre la economía y las finanzas», los autores incluyen como ejemplo las siguientes dos sugerencias:

\section{- «Medidas de imposición fiscal a las transacciones financie-} ras». Está claro que los autores no están por la labor de reducir el Estado, sino de seguir aumentándolo. «Dicha imposición sería muy útil para promover el desarrollo global y sostenible, según los principios de la justicia social y de la solidaridad; y podría contribuir a la constitución de una reserva mundial de apoyo a los Países afectados por la crisis, así como al saneamiento de su sistema monetario y financiero». Es discutible que ese nuevo impuesto pueda conseguir en la práctica todas las ideas grandilocuentes que proponen los autores.

- «Recapitalización de los bancos, incluso con fondos públicos». Recapitalizar los bancos con fondos públicos está muy bien, pero primero habría que sanear a esos bancos, liquidar los no viables, y cambiar a los gestores del resto que necesite ayudas públicas, ¿o pasamos directamente a la recapitalización con fondos públicos, esos que tanto necesitamos todos y de los que el Estado dispone con tanta generosidad? Condicionando el apoyo [público] a comportamientos «virtuosos» y finalizados a desarrollar la «economía real». Ya ha habido recapitalizaciones con fondos públicos. ¿Han sido éstas causa de comportamientos virtuosos por parte de los banqueros o han vuelto a las andadas? ¿Se ha desarrollado la economía real o escasea el crédito más que nunca? Agradecemos las buenas intenciones de los autores, pero un poco de realismo también es necesario. 
III

\section{PROPUESTAS INCOMPLETAS Y CONFUSAS}

La Nota indica que «vale la pena recordar que, entre el 1900 y el 2000, la población mundial casi se cuadruplicó y que la riqueza producida a nivel mundial creció en modo mucho más rápido» (gracias sobre todo al libre mercado). Pero a la vez, denuncia que, «sin embargo, no ha aumentado la equitativa distribución de la riqueza; sino que en muchos casos ha empeorado». ¿Qué ha impedido una distribución más justa de la riqueza, para privar a quien trabaja y produce de los frutos de su trabajo, sino la ausencia de respeto a los derechos de propiedad, como nos enseña el Catecismo (n. 2.431)? Ahí donde el colectivismo, el estatismo y la corrupción han conculcado los derechos de propiedad es donde las desigualdades injustas en el reparto de la riqueza claman con más fuerza al cielo.

Pero puede que los autores de la Nota no vayan por ahí. Esa nueva Autoridad pública de competencia universal está llamada a realizar «una distribución igualitaria de la riqueza mundial, incluso mediante formas inéditas de solidaridad fiscal global». Adiós a los derechos de propiedad; adiós a la solidaridad verdadera. No se puede hablar de amor si no hay libertad, ¿o la verdadera solidaridad a la que aspira el pensamiento social cristiano se impone? ¿Es utópico fundar soluciones técnicas pensadas para un hombre hecho por y para el Amor? ¿Son necesarios eufemismos socialdemócratas, como «solidaridad fiscal», para presentar un pensamiento social cristiano?

Tampoco está claro qué quieren decir los autores cuando entienden que en los orígenes de la crisis se encuentra «una ideología, de una forma de "apriorismo económico", que pretende tomar de la teoría las leyes del funcionamiento del mercado y las denominadas leyes del desarrollo capitalista, exagerando algunos de sus aspectos.» ¿Dónde ven los autores «apriorismo económico» cuando precisamente todo el pensamiento económico moderno, que nos ha traído a esta crisis, está fundado en el empirismo y en el positivismo? Otra cosa es que la teoría económica con la que los economista empiristas y positivistas explicaban sus observaciones de la realidad estuviesen equivocadas, precisamente por ser 
de naturaleza intervencionista y tratar al hombre como una pieza dentro de una maquinaria social que es fácilmente manejable con modelos matemáticos. Un «buen apriorismo», sin embargo, es necesario si realmente queremos descubrir las leyes inscritas (por Dios, si me permiten) en la propia dinámica social. Cierto apriorismo es también necesario si creemos que la Autoridad mundial debe estar regida por la Ley Natural.

IV

PROPUESTAS QUE OLVIDAN LA REALIDAD

La Nota entiende que «un liberalismo económico sin reglas y sin supervisión» ha impulsado al mundo en esta dirección extremadamente problemática incluso para la Paz. ¿Es posible que los autores puedan afirmar tal cosa, y en particular de un sector financiero híper-regulado e híper-supervisado por los poderes públicos? Otra cosa es con qué fin se hiper-regule y con qué fin se hiper-supervise, pero junte Ud. las páginas de regulación que son necesarias para cualquier actividad económica, no digamos si es una actividad que los poderes públicos pretenden privilegiar en favor de unos grupos y en contra de todos los demás, como la banca, y podrá levantar torres de varios pisos de altura. Junte Ud. todos funcionarios, comisión, agencias, consejo, grupo de coordinación nacionales e internacionales que supervisan el sector financiero, por ejemplo, y verá que son legión.

Piden los autores una Autoridad pública de competencia mundial que gobierne la economía y las políticas de desarrollo. ¿No es suficiente la evidencia del colapso económico de los regímenes colectivistas en el gobierno de la economía? ¿No está siendo suficiente la evidencia de la ineficiencia de las políticas de desarrollo gobernadas por los Estados?

Esta falta de realismo de los autores está presente cuando pide que esta Autoridad pública con competencia universal se cree de forma voluntaria, que los países se adhieran por convicción. Esto puede ser así, pero sería entonces el final de un proceso de acercamiento mutuo, no el resultado de un diseño creado desde una burocracia internacional. 


\section{$\mathrm{V}$ ¿UNA NOTA CON SESGO IDEOLÓGICO?}

Todo hace pensar que sí, por ejemplo, cuando dice: «A la base de las disparidades y de las distorsiones del desarrollo capitalista, se encuentra en gran parte, además de la ideología del liberalismo económico, la ideología utilitarista». ¿Qué se pretende al mezclar el liberalismo económico, el modo más eficaz de generar riqueza en beneficio de todos (y más humano que el «socialismo económico»), con la ideología utilitarista, una patología del comportamiento humano que niega cualquier espíritu de solidaridad que trascienda la utilidad personal?

Apunta la Nota que en los años veinte «algunos economistas ya habían puesto en guardia para que no se diera crédito excesivamente, en ausencia de reglas y controles, a esas teorías, que hoy se han transformado en ideologías y praxis dominantes a nivel internacional.» Sería muy revelador para conocer el sustrato intelectual de esta Nota saber a qué economistas se refieren los autores.

Muchos católicos se acercan de buena fe a las enseñanzas sociales del Magisterio, y ante ciertas soluciones técnicas planteadas desde ideologías concretas dejan de seguir considerando los textos. Entienden que tales soluciones técnicas no les obligan moralmente. Otros católicos que su amor a la Iglesia lo extienden también a defender cualquier cosa que salga de los entresijos clericales vaticanos, tratan de reinterpretar los textos para que digan lo que no dicen pero que les gustaría que dijeran. Propuestas de actuación política y económica, discutibles desde un punto de vista moral y económico, cuando se representan como parte de un texto vaticano de sana doctrina y sabio magisterio, hacen daño.

\section{VI}

UNA NOTA QUE NOS COMPROMETE

En este artículo solo he querido tocar algunos de los puntos que trata la Nota. Las propuestas y matices son numerosísimos y comentarlos uno por uno extendería demasiado este artículo, que ya es largo. 
Pese a que esta Nota pueda no representar el pensamiento ni las aspiraciones sociales de muchos católicos, no es un documento para olvidar. Es un documento para comprometerse en la línea en la que pide la misma Nota: «las comunidades de creyentes deben en primer lugar preguntarse si los medios de los que dispone la familia humana para la realización del bien común mundial son los más adecuados». La Nota nos compromete a todos a llevar a cabo un programa de trabajo que dé respuesta a esta pregunta, y las propuestas que plantea al G20 el Pontificio Consejo de Justicia y Paz indican claramente que este programa de trabajo es urgente. 